\title{
Effects of Root-zone Cooling with Short-day Treatment in Pot-grown Strawberry (Fragaria $\times$ ananassa Duch.) Nurseries on Flowering and Fruit Production
}

\author{
Shinji Mizuno*, Yoshiyuki Muramatsu, Akira Tateishi, Keiichi Watanabe, \\ Fumie Shinmachi, Masaji Koshioka and Satoshi Kubota
}

College of Bioresource Sciences, Nihon University, Fujisawa 252-8510, Japan

\begin{abstract}
We applied the New Root-zone Environmental Control System (N.RECS), which comprises floor heating panels with chilled or heated water flow and heat-insulating pot trays, to cool the root zone of pot-grown strawberry (Fragaria $\times$ ananassa Duch.) nurseries in late summer, and investigated the effects on the subsequent flowering and yield in a super-forcing culture. Cooling at around $20^{\circ} \mathrm{C}$ with short-day (8-h daylength) treatment for 22 days accelerated and stabilized the flower bud formation of two June-bearing cultivars, 'Nyoho' and 'Tochiotome'. The temperature at the soil surface, where the crown is located, was around $23^{\circ} \mathrm{C}$ on average during root-zone cooling, possibly acting as a cold stimulus on the shoot apical meristem, which initiated flowering. Root-zone cooling did not affect the development of new leaves during treatment. Combined root-zone cooling with short-day treatment promoted anthesis of the first inflorescence to the same degree as conventional night cooling, but neither did so alone. Weight-based early marketable yield before December was doubled but the total yield during October to March was not increased. These data suggest that root-zone cooling with short-day treatment of June-bearing strawberries may be applicable for super-forcing culture harvested from October to mid-November.
\end{abstract}

Key Words: flower bud differentiation, June-bearing, night cooling, N.RECS, yield.

\section{Introduction}

Production techniques based on localized heating or cooling of plant organs are used in protected horticulture. Roots, shoot tips, flowers and fruits are sensitive to temperature changes, and localized temperature control of these parts can promote the growth of various organs, induce flowering, improve yield and quality, and reduce heating and cooling energy (Kawasaki and Yoneda, 2019). Localized heating of tomato shoot tips in winter shortened the interval of flower cluster appearance, impacted commercial fruit yield, and reduced energy consumption (Kawasaki et al., 2010, 2011). Heating the root-zone of potted flowers in cold

Received; February 25, 2021. Accepted; July 5, 2021.

First Published Online in J-STAGE on September 17, 2021.

Special Issue "Plant factory and modern greenhouse".

This work was supported by a grant from a project study in Nihon University President's Special Research.

Part of this study was presented at the 2019 Spring Meeting of the Japanese Society for Horticultural Science.

* Corresponding author (E-mail: mizuno.shinji@nihon-u.ac.jp). air increased the number of leaves and aboveground dry matter, promoted flowering, and reduced energy consumption in comparison with heating ambient air (Kubota et al., 2013; Muramatsu et al., 2017). Rootzone cooling of tomato nursery plants during the daytime in hot periods promoted both shoot and root growth and increased fruit yield (Kinoshita et al., 2012). Cooling of cucumber roots during heat kept fruit yield higher and improved root growth, even when the aerial parts were exposed to high air temperatures (Moon et al., 2007). The balance between vegetative growth and flower bud formation of pot-grown cyclamen during a hot summer can be controlled by cooling the root-zone (Muramatsu et al., 2015).

Many cultivation techniques using local temperature control have been used in strawberries (Fragaria $\times$ ananassa Duch.), and some have been introduced into commercial production. Root-zone heating of strawberries in forcing culture prevents the stagnation of growth during severe cold, accelerates flowering of the second lateral flower cluster, and increases the total yield (Shigeno et al., 2001; Kim et al., 2009). Partial 
heating of the strawberry crown - the dwarfed stem and shoot tip-also prevents growth retardation and promotes flowering in the cold season (Sato and Kitajima, 2010; Dan et al., 2019). Local cooling techniques have been developed to stabilize strawberry flowering and fruit production in the hot season. Latent-heat cooling of the growth medium in a high-bench culture system during early autumn accelerated flower bud emergence of the first lateral flower cluster in the forcing culture of a June-bearing cultivar (Ikeda et al., 2007). Crown cooling with chilled water flow from summer to autumn promoted flowering of both everbearing (Oowashi et al., 2014) and June-bearing (Dan et al., 2015; Hidaka et al., 2017) strawberry cultivars, and thus impacted fruit yield.

In Japan, most strawberry fruits are produced by a forcing culture that begins harvest in late November to December in Honshu, Shikoku, and Kyushu; and Junebearing cultivars are commonly used. Pot-grown nursery plants, each of which has a flower bud of the first inflorescence differentiated under natural cool short-day (SD) conditions during late summer to early autumn, are transplanted into greenhouses in September. Since the market price of strawberries tends to be higher from autumn to year-end than later in the season, further forcing of the harvest period would likely increase farmers' incomes. Several techniques for artificially accelerating flower bud differentiation of nurseries, such as night cooling with SD treatment ("Yarei"), continuous low-temperature storage ("Ankoku-reizo"), and intermittent low-temperature storage ("Kanketsureizo"), have been established (Yoshida and Nishimoto, 2020), and they enable a super-forcing culture that begins harvest in October to mid-November. However, the commercial use of these super-forcing techniques is limited owing to high initial and running costs for dedicated facilities or to instability of the inductive stimulus.

Recently, we developed a New Root-zone Environmental Control System (N.RECS) by combining floor heating panels and heat-insulating pot trays (Kubota et al., 2018). N.RECS can supply chilled or heated water, enabling both root-zone heating and cooling. The panel size can be changed and the pot tray can be removed, making it applicable to various crops. Here, we applied N.RECS to cool the root-zone of potgrown strawberry nurseries in late summer and investigated the effects on the subsequent flowering and yield in super-forcing culture.

\section{Materials and Methods}

\section{Plant materials and growth condition of nurseries}

Strawberry nurseries were grown on benches in a greenhouse at Nihon University (Fujisawa, Kanagawa, Japan) in 2017 and 2018. From late May, child stocks of June-bearing strawberries ('Tochiotome' and 'Nyoho') were propagated by runners from mother plants, then grown in soft polyethylene pots $(9 \mathrm{~cm}$ diameter, $8 \mathrm{~cm}$ depth) containing conventional culture soil for fruit vegetables. The runners were cut in late July. A granulated inorganic fertilizer was applied at $\mathrm{N}: \mathrm{P}_{2} \mathrm{O}_{5}: \mathrm{K}_{2} \mathrm{O}=60: 60: 60 \mathrm{mg} /$ pot every month after rooting until early August. By removing aged leaves, the plant leaf number was managed at $\leq 3.5$ (expanded leaf is counted as 1.0, unexpanded as 0.5 ) until treatment and at $\leq 4.5$ after treatment.

\section{Treatments for pot-grown nurseries}

Root-zone cooling (RC) treatment of pot-grown nurseries was performed using N.RECS (Kubota et al., 2018) or a modified system without pot trays (Fig. 1). In summary, heat exchange panels (HM-600-7A12, $60 \mathrm{~cm} \times 60 \mathrm{~cm}$; Seamless, Japan) and a cross-linked polyethylene pipe $(\varnothing 1 \mathrm{~cm})$ were set in a cultivation bench and a root protection sheet (Lovesheet Black; Unitika, Japan) was laid on top. The bench space measured $9 \mathrm{~m}$ long, $120 \mathrm{~cm}$ wide and $8 \mathrm{~cm}$ deep. Using a heat pump (VEH-304HCD-K; Mitsubishi Electric, Japan), water was chilled to $7^{\circ} \mathrm{C}$ and circulated through the pipe at $1.6-1.8 \mathrm{~L} \cdot \mathrm{min}^{-1}$. The root-zone temperature was monitored by a sensor at $5 \mathrm{~cm}$ below the soil surface of a pot and automatically controlled to $\sim 20^{\circ} \mathrm{C}$ throughout the day by switching the cold-water supply on and off. In 2017, insulated pot trays with 15 holes $(40 \mathrm{~cm} \times 60 \mathrm{~cm}, 8 \mathrm{~cm}$ depth, made of white polystyrene partially coated with aluminium foil to enhance heat

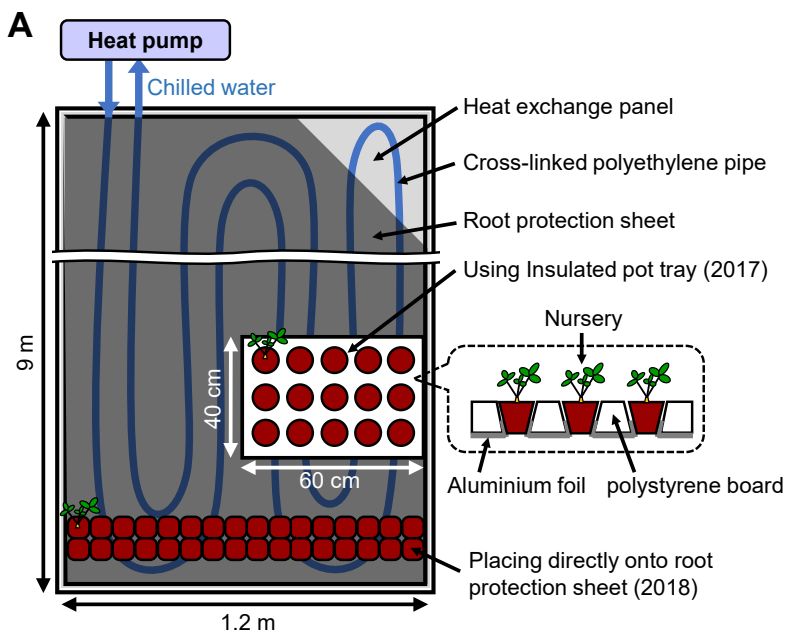

B

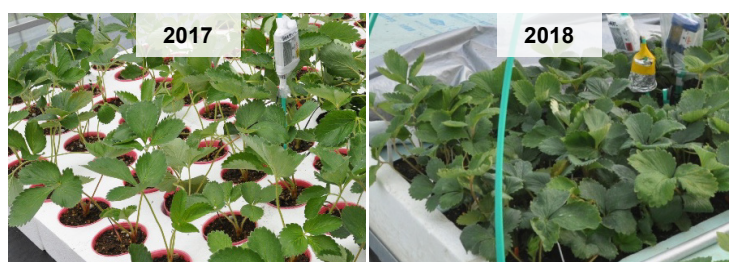

Fig. 1. Root-zone cooling system of strawberry nurseries. (A) Schematic representation of temperature control method. (B) Root-zone cooling treatment using N.RECS (2017) or a modified system without insulated pot trays (2018) 
transfer to the pots) were used. The trays were placed on the root protection sheet. In 2018, pots were placed directly on the sheet without the insulated trays to increase the density of pots and to reduce the risk of anthracnose due to irrigation bounce on the polystyrene board. The plant density during treatments was $63 \mathrm{~m}^{-1}$ of bench in 2017 and $178 \mathrm{~m}^{-1}$ in 2018. Short-day (SD) treatment was carried out using a light-shielding film (White Silver; Tokan Kogyo, Japan): nurseries were entirely covered with the film every day from 17:00 to 09:00 to create an 8-h daylength. Night cooling (NC) treatment was performed every night: nurseries were transferred into a cooling chamber held at $13-14^{\circ} \mathrm{C}$ in the dark at 17:00 and back out to the greenhouse at 09:00. Each treatment used 45-60 plants and was applied for 22 days: 8-30 August 2017 and 9-31 August 2018. Thereafter, the nurseries were grown in a greenhouse until transplanting.

\section{Measuring temperatures}

Air, root-zone, and crown temperatures were recorded at 30-min intervals on temperature recorders (RT-13 or RT-14; Espec, Japan). The air temperature was measured at $10 \mathrm{~cm}$ above the soil surface. The root-zone temperature was sensed at $5 \mathrm{~cm}$ below the soil surface. The crown temperature was monitored by a probe in contact with the crown surface. Thermographic images were taken with a thermal imaging camera (FLIR i7; FLIR Systems, OR, USA).

\section{Analysis of growth and flower bud differentiation of nurseries}

During treatments, we recorded the number of total and removed leaves several times to assess effects on growth. At transplanting, we randomly selected five plants in each treatment, dissected the primary shoot tip under a stereomicroscope, and observed the morphology of the apical meristem. Flower bud development of the first inflorescence was classified into stages $0-8$ as described by Hidaka et al. (2017).

\section{Growth condition after transplanting}

On 7 September 2017 and 10 September 2018, the nurseries were transplanted into raised beds in a greenhouse: the beds were raised by $30 \mathrm{~cm}$ and were $65 \mathrm{~cm}$ wide; rows were spaced $105 \mathrm{~cm}$ apart; and plants were spaced $20 \mathrm{~cm}$ apart at $25 \mathrm{~cm}$ between staggered rows. Six-month-type slow-release fertilizer was applied at $\mathrm{N}: \mathrm{P}_{2} \mathrm{O}_{5}: \mathrm{K}_{2} \mathrm{O}=12: 12: 12 \mathrm{~g} \cdot \mathrm{m}^{-2}$, and only water was supplied during cultivation. Each treatment used a randomized block design with 12 plants $\times 3$ replicates (blocks) in 2017, 12 plants $\times 4$ replicates of 'Tochiotome' in 2018, and 10 plants $\times 4$ replicates of 'Nyoho' in 2018 . Beds were mulched with silver polyethylene film in late September. Flowers were pollinated by honey bees. In winter, the minimum air temperature was maintained at $5-7^{\circ} \mathrm{C}$ by a heat pump and fans.

\section{Evaluating flower development and fruit yield}

The dates of flower bud emergence and anthesis of the first flower in the first inflorescence of each plant were recorded. From October to March, marketable fruits ( $\geq 6.0 \mathrm{~g}$ fresh weight) were harvested from each replicate twice a week, counted, and weighed.

\section{Statistical analysis}

All means were compared by Tukey-Kramer test in BellCurve for Excel v. 3.20 software (Social Survey Research Information, Japan) at the 5\% level.

\section{Results}

In 2017, daily average air temperatures were low in early to mid-August owing to prolonged rain (Fig. 2A). They rose to $\sim 30^{\circ} \mathrm{C}$, but temperatures below $25^{\circ} \mathrm{C}$ continued after treatment until transplanting on 7 September. In 2018, temperatures were high throughout summer to autumn, and were $>25^{\circ} \mathrm{C}$ on most days until transplanting on 10 September.

Diurnal changes in temperatures around leaves, on the crown surface, and in the root-zone during 22 days in August were consistent between years in each treat-

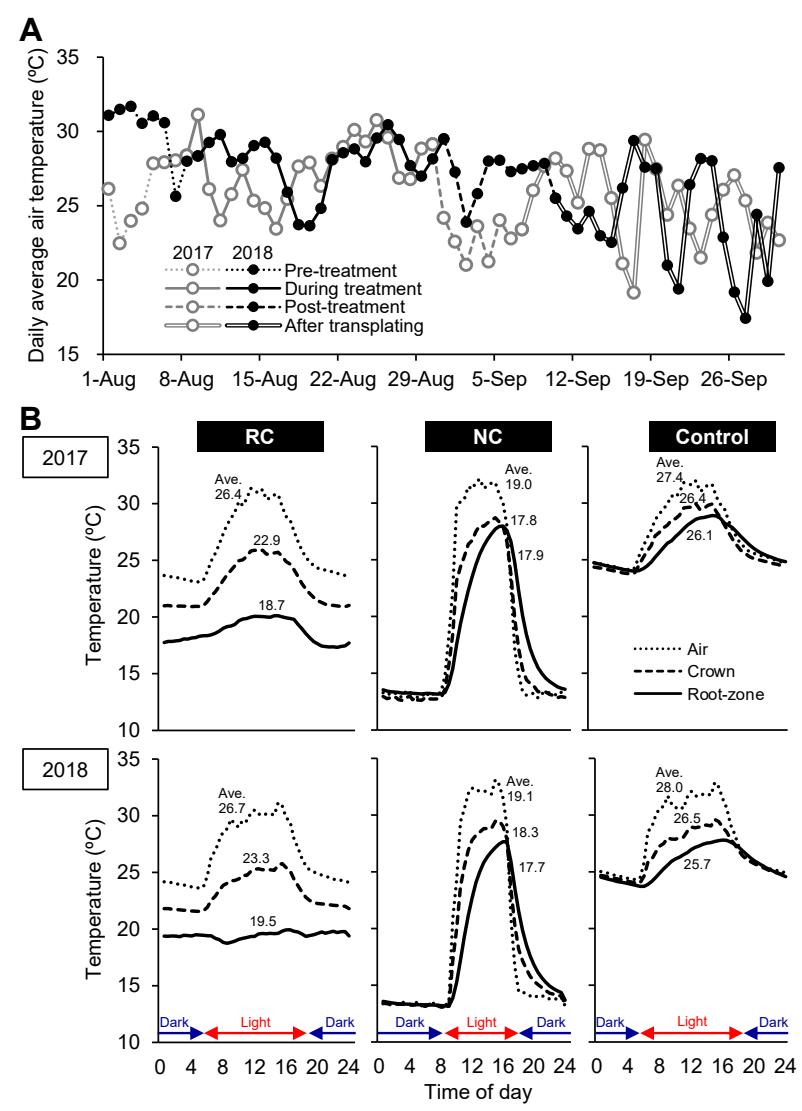

Fig. 2. (A) Changes in daily average air temperature in greenhouse from August to September. (B) Diurnal changes in mean air, crown surface, and root-zone soil temperatures inside greenhouse in each treatment during 8-30 August 2017 and 9-31 August 2018. RC, root-zone cooling; NC, night cooling treatment $\left(8 \mathrm{~h} \mathrm{light} / 16 \mathrm{~h}\right.$ dark at $\left.13-14^{\circ} \mathrm{C}\right)$; Control, no treatment. 
ment (Fig. 2B). RC maintained the root-zone temperature at $18-20^{\circ} \mathrm{C}$ throughout the day and clearly chilled the soil surface, where the plant crowns grow (Fig. 3): average crown temperatures were $\sim 23^{\circ} \mathrm{C},>3^{\circ} \mathrm{C}$ lower than in the control (Fig. 2B). Average air temperatures, in contrast, were $>26^{\circ} \mathrm{C}$ in both years, with $\leq 1.5^{\circ} \mathrm{C}$ difference from the control. The additional effect of SD treatment on air, crown, and root-zone temperatures was negligible $\left(\leq 0.5^{\circ} \mathrm{C}\right.$ difference in each, data not shown). NC chilled the whole plants and kept the temperatures at $\sim 13^{\circ} \mathrm{C}$ in the dark for $16 \mathrm{~h}$ every day. To evaluate growth during treatments, we investigated changes in the numbers of leaves. At the beginning of the treatments, all nurseries were adjusted to have 2.53.5 leaves (on average 3.0 , Fig. 4). RC alone and $\mathrm{RC}+\mathrm{SD}$ did not affect the cumulative number of leaves at the end of the treatments. In contrast, $\mathrm{NC}$ of 'Tochiotome' retarded the expansion of new leaves in both years.

To clarify whether RC accelerates floral development, we investigated the flower bud differentiation stage at transplanting and the dates of subsequent flower bud emergence and anthesis. In 2017, RC + SD of 'Tochiotome' facilitated flower bud development to the same level as NC, but RC and SD alone had no clear effect (Table 1). RC + SD and NC both facilitated flower bud emergence and anthesis of the first inflorescence: the median anthesis date was 14 October, 10 days earlier than in the control. In 2018, RC+SD of both 'Tochiotome' and 'Nyoho' clearly enhanced flower bud development at transplanting. The median anthesis date was 7 October in 'Tochiotome' and 11 October in 'Nyoho', $>40$ days earlier than in each control. RC $+\mathrm{SD}$ also helped to restrain prolongation of the flower-

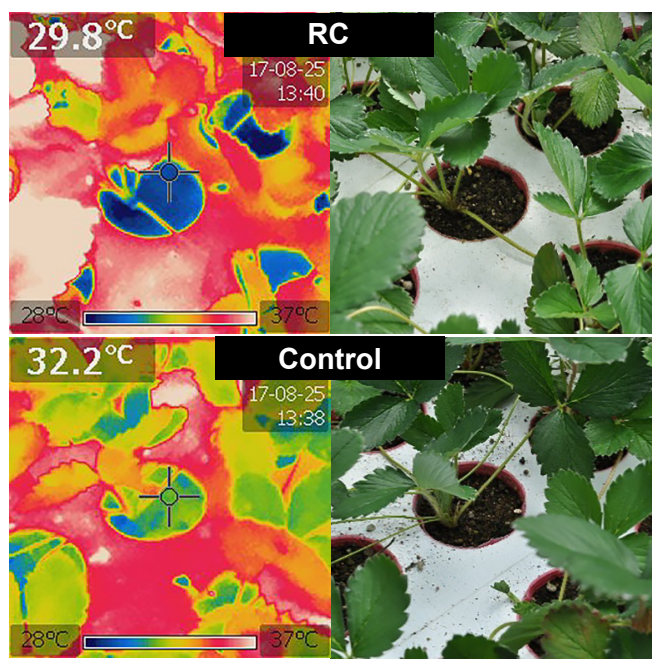

Fig. 3. Thermograph (left) and photograph (right) of pot-grown 'Nyoho' nurseries in insulated pot trays. Images were taken under cloudy weather on the afternoon of 25 August 2017. The soil temperature around the center marker (cross) is shown at the upper left of the thermograph. RC, root-zone cooling; Control, no treatment. ing season, whereas plants treated with $\mathrm{RC}$ alone or untreated showed severe decentralization in the periods of flower bud emergence and anthesis, with a standard deviation $>20$ days.

We investigated the weight-based marketable yield and the number of fruits (Table 2). In comparison with the untreated control plants, RC $+\mathrm{SD}$ of 'Tochiotome' and 'Nyoho' doubled the early marketable yield during October-November in both years. That of 'Tochiotome' was the same as in NC, but RC or SD treatment alone had no effect. In 2017, the December yield was lower in $\mathrm{RC}+\mathrm{SD}$ than in the control, but still higher than in NC. No treatments significantly affected the later yields during January to March or the total yield during October to March. However, the total fruit harvested from the $\mathrm{RC}+\mathrm{SD}$ plants was 28.4 fruit/plant, $1.2 \times$ that of the control plants. In 2018, the periodic yields in December and January-March, the total yield, and the number of fruits in each cultivar were equivalent in all treatments. The cumulative number curves of marketable fruit in the $\mathrm{RC}+\mathrm{SD}$ and $\mathrm{NC}$ plants were equivalent, and in 2018 rose markedly earlier than in the control plants

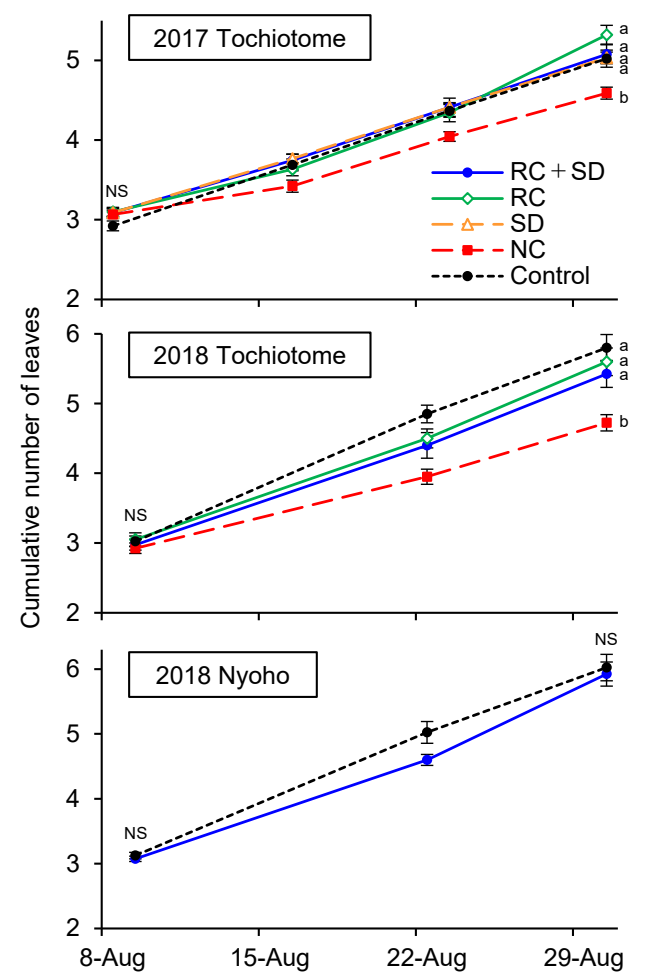

Fig. 4. Changes in cumulative number of leaves of pot-grown strawberry nurseries in each treatment. Remaining leaf number of all nurseries was initially adjusted to $2.5-3.5$ and then managed at $\leq 4.5$ by removing aged leaves during treatment. An unexpanded leaf was counted as 0.5 . RC, root-zone cooling; $\mathrm{SD}$, short-day treatment ( $8 \mathrm{~h}$ light $/ 16 \mathrm{~h}$ dark); $\mathrm{NC}$, night cooling treatment $\left(8 \mathrm{~h} \mathrm{light} / 16 \mathrm{~h}\right.$ dark at $\left.13-14^{\circ} \mathrm{C}\right)$; Control, no treatment. Data are mean \pm standard error $(n=45$ in $2017, n=20$ in 2018). Treatment values with the same letter are not significantly different by Tukey-Kramer test $(\alpha=0.05)$; NS, not significant. 
Table 1. Effect of root-zone cooling and short-day treatment of pot-grown strawberry nurseries on floral development.

\begin{tabular}{|c|c|c|c|c|c|c|c|c|c|c|c|c|c|}
\hline \multirow{3}{*}{ Year } & \multirow{2}{*}{ Cultivar } & \multirow{2}{*}{ Treatment $^{z}$} & \multirow{2}{*}{\multicolumn{5}{|c|}{$\begin{array}{l}\text { Flower bud development } \\
\text { stage at planting }\end{array}$}} & \multicolumn{3}{|c|}{ Flower bud emergence } & \multicolumn{3}{|c|}{ Anthesis } \\
\hline & & & & & & & & \multicolumn{2}{|c|}{$\operatorname{Median}^{\mathrm{x}}$} & \multirow{2}{*}{$\frac{\mathrm{SD}^{\mathrm{w}}}{4.1}$} & \multicolumn{2}{|c|}{$\operatorname{Median}^{\mathrm{x}}$} & \multirow{2}{*}{$\frac{\mathrm{SD}^{\mathrm{w}}}{5.7}$} \\
\hline & \multirow{5}{*}{ Tochiotome } & $\mathrm{RC}+\mathrm{SD}$ & 7 & 5 & 5 & 4 & 3 & Oct. 5 & $a^{v}$ & & Oct. 14 & a & \\
\hline \multirow{4}{*}{2017} & & $\mathrm{RC}$ & 4 & 3 & 3 & 3 & 1 & Oct. 9 & $\mathrm{bc}$ & 7.4 & Oct. 20 & $\mathrm{~b}$ & 11.5 \\
\hline & & SD & 3 & 1 & 1 & 1 & 0 & Oct. 8 & $a b$ & 4.5 & Oct. 20 & $\mathrm{~b}$ & 5.8 \\
\hline & & $\mathrm{NC}$ & 6 & 6 & 6 & 4 & 3 & Oct. 5 & $\mathrm{a}$ & 3.8 & Oct. 14 & $\mathrm{a}$ & 5.1 \\
\hline & & Control & 5 & 3 & 2 & 1 & 0 & Oct. 11 & $\mathrm{c}$ & 10.9 & Oct. 24 & $\mathrm{~b}$ & 15.8 \\
\hline \multirow{6}{*}{2018} & \multirow{4}{*}{ Tochiotome } & $\mathrm{RC}+\mathrm{SD}$ & 8 & 7 & 7 & 6 & 6 & Sep. 29 & $\mathrm{a}$ & 7.9 & Oct. 7 & $\mathrm{a}$ & 10.1 \\
\hline & & $\mathrm{RC}$ & 8 & 7 & 0 & 0 & 0 & Oct. 14 & $a b$ & 24.1 & Oct. 29 & $a b$ & 32.1 \\
\hline & & $\mathrm{NC}$ & 7 & 7 & 6 & 6 & 5 & Oct. 2 & a & 6.6 & Oct. 11 & a & 8.5 \\
\hline & & Control & 6 & 1 & 0 & 0 & 0 & Oct. 30 & b & 25.7 & Nov. 18 & $\mathrm{~b}$ & 36.4 \\
\hline & \multirow{2}{*}{ Nyoho } & $\mathrm{RC}+\mathrm{SD}$ & 8 & 7 & 7 & 6 & 3 & Oct. 2 & $\mathrm{a}$ & 10.4 & Oct. 11 & $\mathrm{a}$ & 14.2 \\
\hline & & Control & 2 & 0 & 0 & 0 & 0 & Nov. 3 & $\mathrm{~b}$ & 21.9 & Nov. 21 & $\mathrm{~b}$ & 29.9 \\
\hline
\end{tabular}

${ }^{\mathrm{z}} \mathrm{RC}$, root-zone cooling; SD, short-day treatment $\left(8 \mathrm{~h}\right.$ light/16 h dark); $\mathrm{NC}$, night cooling treatment $\left(8 \mathrm{~h} \mathrm{light} / 16 \mathrm{~h}\right.$ dark at $\left.13-14^{\circ} \mathrm{C}\right)$; Control, no treatment.

${ }^{y}$ Five plants were investigated on 7 Sep. 2017 and 10 Sep. 2018 and morphology of apical meristem was classified into nine stages: 0, vegetative apex (before flower bud differentiation); 1, early apex enlargement; 2, later apex enlargement; 3, apex division; 4, sepal development; 5, petal development; 6, stamen development; 7, pistil development; 8, epidermal hair development.

${ }^{x}$ Mean of median of $10-12$ plants in respective replicates $(n=3-4)$.

${ }^{\mathrm{w}}$ Standard deviation of individual plants $(\mathrm{n}=36-48)$.

v Treatment values with the same letter are not significantly different by Tukey-Kramer test $(\alpha=0.05)$.

Table 2. Effect of root-zone cooling and short-day treatment of pot-grown strawberry nurseries on fruit yield.

\begin{tabular}{|c|c|c|c|c|c|c|c|}
\hline \multirow{2}{*}{ Year } & \multirow{2}{*}{ Cultivar } & \multirow{2}{*}{ Treatment $^{z}$} & \multicolumn{4}{|c|}{ Marketable yield (g/plant) } & \multirow{2}{*}{$\begin{array}{l}\text { Number of } \\
\text { fruits/plant }\end{array}$} \\
\hline & & & Oct.-Nov. & Dec. & Jan.-Mar. & Total & \\
\hline \multirow{5}{*}{2017} & \multirow{5}{*}{ Tochiotome } & $\mathrm{RC}+\mathrm{SD}$ & $37 a^{y}$ & $73 \mathrm{~b}$ & $338 \mathrm{a}$ & $448 \mathrm{a}$ & $28.4 \mathrm{a}$ \\
\hline & & $\mathrm{RC}$ & $20 \mathrm{ab}$ & $91 \mathrm{ab}$ & $322 \mathrm{a}$ & $433 \mathrm{a}$ & $26.0 \mathrm{ab}$ \\
\hline & & SD & $20 \mathrm{ab}$ & $96 \mathrm{a}$ & $265 \mathrm{a}$ & $381 \mathrm{a}$ & $24.7 \mathrm{ab}$ \\
\hline & & $\mathrm{NC}$ & $37 \mathrm{a}$ & $58 \mathrm{c}$ & $274 \mathrm{a}$ & $369 \mathrm{a}$ & $23.8 \mathrm{~b}$ \\
\hline & & Control & $16 \mathrm{~b}$ & $95 \mathrm{a}$ & $257 \mathrm{a}$ & $368 \mathrm{a}$ & $23.0 \mathrm{~b}$ \\
\hline \multirow{6}{*}{2018} & \multirow{4}{*}{ Tochiotome } & $\mathrm{RC}+\mathrm{SD}$ & $56 \mathrm{a}$ & $31 \mathrm{a}$ & $205 \mathrm{a}$ & $292 \mathrm{a}$ & $19.4 \mathrm{a}$ \\
\hline & & $\mathrm{RC}$ & $28 \mathrm{~b}$ & $33 \mathrm{a}$ & $233 \mathrm{a}$ & $294 \mathrm{a}$ & $17.8 \mathrm{a}$ \\
\hline & & $\mathrm{NC}$ & $58 \mathrm{a}$ & $32 \mathrm{a}$ & $219 \mathrm{a}$ & $309 a$ & $20.0 \mathrm{a}$ \\
\hline & & Control & $22 \mathrm{~b}$ & $37 \mathrm{a}$ & $238 \mathrm{a}$ & $297 \mathrm{a}$ & $17.6 \mathrm{a}$ \\
\hline & \multirow{2}{*}{ Nyoho } & $\mathrm{RC}+\mathrm{SD}$ & $41 \mathrm{a}$ & $41 \mathrm{a}$ & $157 \mathrm{a}$ & $239 \mathrm{a}$ & $21.5 \mathrm{a}$ \\
\hline & & Control & $18 \mathrm{~b}$ & $29 \mathrm{a}$ & $194 \mathrm{a}$ & $241 \mathrm{a}$ & $18.9 \mathrm{a}$ \\
\hline
\end{tabular}

${ }^{\mathrm{z}} \mathrm{RC}$, root-zone cooling; SD, short-day treatment $\left(8 \mathrm{~h}\right.$ light $/ 16 \mathrm{~h}$ dark); $\mathrm{NC}$, night cooling treatment $\left(8 \mathrm{~h} \mathrm{light} / 16 \mathrm{~h}\right.$ dark at $\left.13-14^{\circ} \mathrm{C}\right)$; Control, no treatment.

${ }^{y}$ Treatment values with the same letter are not significantly different by Tukey-Kramer test $(\alpha=0.05)$.

(Fig. 5). Irrespective of year and cultivar, the cumulative number increment in $\mathrm{RC}+\mathrm{SD}$ and $\mathrm{NC}$ stagnated slightly in January but recovered after mid-February.

\section{Discussion}

We demonstrated that root-zone cooling $(\mathrm{RC})$ of potgrown strawberry nurseries effectively chilled the crown in addition to the root-zone. When RC was performed together with a short-day (SD) treatment in late summer, floral development was facilitated and the early yield in October-November increased. These results suggest that the root-zone cooling technique may be applicable for super-forcing culture of June- bearing strawberries.

We tested two cooling schemes: using insulated pot trays in 2017 and placing pots directly on the heat exchange panel in 2018. We concluded that trays were not necessary because the root-zone temperature was chilled to $<20^{\circ} \mathrm{C}$ throughout the day even without insulation. Kinoshita et al. (2012) previously reported a root-zone cooling technique of pot-grown nurseries using cold water flow in polyvinyl chloride pipe, but this method cannot keep the root-zone temperature under $25^{\circ} \mathrm{C}$ in daytime during the hot season due to a lack of cooling capacity. Our N.RECS-based technique can maintain lower root-zone temperature, leading to a 


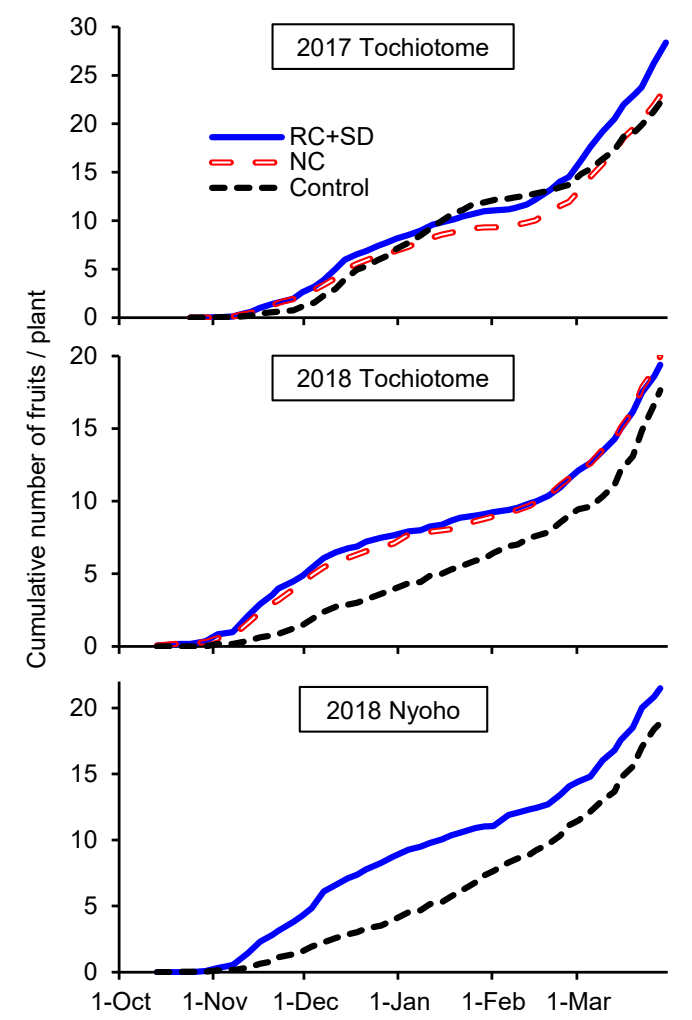

Fig. 5. Changes in cumulative number of marketable fruits by each treatment in pot-grown strawberry nurseries. RC, root-zone cooling; SD, short-day treatment $(8 \mathrm{~h}$ light $/ 16 \mathrm{~h}$ dark); $\mathrm{NC}$, night cooling treatment $\left(8 \mathrm{~h}\right.$ light $/ 16 \mathrm{~h}$ dark at $\left.13-14^{\circ} \mathrm{C}\right)$; Control, no treatment.

higher physiological effect of the local temperature control. $\mathrm{RC}+\mathrm{SD}$ promoted flowering in each year, but in 2017, flower bud differentiation had occurred at transplanting even in most of the untreated control plants (Table 1), possibly because daily average temperatures were $<25^{\circ} \mathrm{C}$ in early September 2017 (Fig. 2A), acting as a cold stimulus to differentiate flower buds. The promotion of flowering by RC + SD was marked in 2018, when temperatures were high in early September. Global warming may cause regular high temperatures, which in summer and autumn would destabilize flower bud differentiation. Thus, the root-zone cooling technique can be used not only in promoting, but also in stabilizing, flower bud differentiation of strawberry plants under warmer conditions.

The night cooling (NC) technique moves the harvest period to earlier than conventional forcing cultivation. The effects on the induction of flowering and subsequent increase in early yields by $\mathrm{RC}+\mathrm{SD}$ and $\mathrm{NC}$ were equivalent. Since the components of N.RECS are being improved and cost reduction promoted for commercial use, we cannot state clearly the advantage of the total cost, at present, compared to conventional techniques such as "Yarei" (NC). However, a dedicated $\mathrm{NC}$ facility is difficult to use for the production of other crops, whereas N.RECS has expandability and versatili- ty: growers can choose panel size and switch between cooling and heating of the root-zone. For example, we previously demonstrated the application of root-zone heating to pot-grown flowers in winter (Kubota et al., 2018). SD treatment can be automated by timercontrolled shading of a bench or an entire greenhouse. Year-round operation of N.RECS may increase the income of farmers or nursery producers.

Environmental factors triggering flower bud differentiation of strawberry have been explained traditionally by the relationship between daylength and air temperature. In the range of 16 to $28^{\circ} \mathrm{C}$, as in late summer to early autumn, June-bearing strawberry cultivars initiate flower buds only under a daylength of $<13 \mathrm{~h}$ (Ito and Saito, 1962). Under SD (8-h light) condition, 'Tochiotome' and 'Nyoho' require an average air temperature of $\leq 24^{\circ} \mathrm{C}$ to initiate flower buds (NARO, 2008). The addition of RC improved this, even though the average temperature during the treatment exceeded $26^{\circ} \mathrm{C}$ (Fig. 2B). This result suggests that local cooling of the root-zone of strawberry at $\sim 20^{\circ} \mathrm{C}$ is a useful technique to accelerate flower bud formation even at high air temperatures. In contrast, promotion of flower bud development by RC or SD alone was insufficient for the early flowering 'Tochiotome' and 'Nyoho'. If recent cultivars such as the extremely early flowering 'Kaorino' (Kitamura et al., 2015) and the everbearing 'Yotsuboshi' (Mori et al., 2015), in which natural high temperatures during long-day treatment tend to delay flowering induction (Inokuchi et al., 2016), are used, $\mathrm{RC}$ may be effective, even without SD, to facilitate and stabilize flowering in summer.

The seasonal flowering habit of both octoploid garden strawberry $(F \times$ ananassa $)$ and diploid woodland strawberry ( $F$. vesca) is controlled by the key floral repressor TERMINAL FLOWER1 (TFL1) in the shoot apical meristem, but little is known about the temperature regulation of TFL1 (Hytönen and Kurokura, 2020). Our study shows that root-zone cooling of pot-grown nurseries also chills the crown. Hidaka et al. (2017) showed that local cooling of the crown to $10-20^{\circ} \mathrm{C}$ induced flower bud differentiation of June-bearing strawberries. These observations suggest that the conduction of a low temperature to the shoot apical meristem is sufficient to induce flower bud differentiation via the downregulation of TFL1. Further investigations of the response of flowering genes to local temperatures may help to optimize the thermal conditions for inducing floral transition in strawberries.

\section{Acknowledgements}

We would like to thank the students of Nihon University, especially C. Arakawa, S. Fujisawa, M. Yoshihama, T. Saito, A. Fukushima, N. Yamada, T. Kohyama, F. Kodama, M. Nagasaki and R. Kamiya for providing technical assistance in cultivation and greenhouse management. 


\section{Literature Cited}

Dan, K., W. Sugeno, S. Nakahara, N. Goto, Y. Honma, M. Yusa, Y. Iwasaki, I. Takano, S. Takayama, K. Hidaka, T. Takayama and H. Imamura. 2019. Forcing culture of strawberries in Miyagi using a crown-temperature control technique. Bull. NARO Kyushu Okinawa Agric. Res. Cent. 68: 10-21 (In Japanese with English abstract).

Dan, K., W. Sugeno, S. Nakahara, N. Goto, Y. Iwasaki, I. Takano, M. Okimura, K. Hidaka, T. Takayama and H. Imamura. 2015. Experiment on the crown-temperature control technique in forcing culture of strawberries in Miyagi. Bull. NARO Kyushu Okinawa Agric. Res. Cent. 64: 1-11 (In Japanese with English abstract).

Hidaka, K., K. Dan, H. Imamura and T. Takayama. 2017. Crowncooling treatment induces earlier flower bud differentiation of strawberry under high air temperatures. Environ. Control. Biol. 55: 21-27.

Hytönen, T. and T. Kurokura. 2020. Control of flowering and runnering in strawberry. Hort. J. 89: 96-107.

Ikeda, T., K. Yamazaki, H. Kumakura and H. Hamamoto. 2007. Effect of cooling of medium on fruit set in high-bench strawberry culture. HortScience, 42: 88-90.

Inokuchi, T., H. Ushida, T. Mori, H. Kitamura, J. Kohori, H. Imamura, J. Tsuruyama, M. Nishida, F. Maeda, M. Hamano and F. Kimura. 2016. Long-day treatment to induce flowering in the seed-propagated strawberry cultivar 'Yotsuboshi'. Bull. Kagawa Agr. Exp. Sta. 66: 27-35 (In Japanese with English abstract).

Ito, H. and T. Saito. 1962. Studies on the flower formation in the strawberry plants. I. Effects of temperature and photoperiod on the flower formation. Tohoku J. Agr. Res. 13: 191-203.

Kawasaki, Y. and Y. Yoneda. 2019. Local temperature control in greenhouse vegetable production. Hort. J. 88: 305-314.

Kawasaki, Y., K. Suzuki, K. Yasuba, H. Kawashima, H. Sasaki and M. Takaichi. 2010. Effect of local heating around the tomato shoot apex and flower clusters on plant surface temperature and characteristics related to fruit yield. Hort. Res. (Japan) 9: 345-350 (In Japanese with English abstract).

Kawasaki, Y., K. Suzuki, K. Yasuba and M. Takaichi. 2011. Effect of local air heating by a hanging duct near the tomato shoot apex and flower clusters on vertical temperature distribution, fruit yield and fuel consumption. Hort. Res. (Japan) 10: 395-400 (In Japanese with English abstract).

Kim, Y. S., M. Endo, Y. Kiriiwa, L. Chen and A. Nukaya. 2009. Effects of root zone heating during daytime on the flowering, growth and yield of strawberry 'Akihime' grown in substrate culture. Hort. Res. (Japan) 8: 193-199 (In Japanese with English abstract).

Kinoshita, T., Y. Nakanoa and H. Kawashima. 2012. Effect of duration of root-zone cooling in potted tomato seedlings on plant growth and fruit yield during high-temperature periods. Hort. Res. (Japan) 11: 459-465 (In Japanese with English abstract).

Kitamura, H., T. Mori, J. Kohori, S. Yamada and H. Shimizu.
2015. Breeding and extension of the new strawberry cultivar 'Kaorino' with extremely early flowering and resistance to anthracnose. Hort. Res. (Japan) 14: 89-95 (In Japanese with English abstract).

Kubota, S., M. Endo, S. Hayashi, H. Takahashi, Y. Muramatsu and M. Koshioka. 2013. Regulation of root-zone temperature by root-zone environmental control system affects growth and flowering of Verbena $\times$ hybrida and Pelargonium $\times$ hortorum. Hort. Res. (Japan) 12: 97-102 (In Japanese with English abstract).

Kubota, S., Y. Muramatsu, A. Oshima, M. Otabe, Y. Sugata and M. Koshioka. 2018. Growth regulation of pot flowers by root-zone temperature control using new root-zone environmental control system (N.RECS). Hort. Res. (Japan) 17: 95103 (In Japanese with English abstract).

Moon, J. H., Y. K. Kang and H. D. Suh. 2007. Effect of rootzone cooling on the growth and yield of cucumber at supraoptimal air temperature. Acta Hortic. 761: 271-274.

Mori, T., J. Kohori, H. Kitamura, T. Inokuchi, I. Kato, K. Sone, M. Ishikawa, F. Maeda, M. Fukami, S. Isobe and S. Sato. 2015. Development of $F_{1}$-hybrid strawberry of seed propagation type named 'Yotsuboshi' by collaborative breeding among institutes. Hort. Res. (Japan) 14: 409-418 (In Japanese with English abstract).

Muramatsu, Y., H. Kawano, S. Kubota and M. Koshioka. 2015. Promotion of Growth and Flowering of Cyclamen by Rootzone Cooling during Hot Summer Season. Hort. Res. (Japan) 14: 267-272 (In Japanese with English abstract).

Muramatsu, Y., S. Kubota and M. Koshioka. 2017. Root-zone heating during winter season is effective to promote growth of Impatiens walleriana Hook. f. Hort. Res. (Japan) 16: 295 300 (In Japanese with English abstract).

NARO. 2008. "Temperatures inducing flower bud differentiation under a short-day condition of June-bearing strawberries" (Translated from Japanese). <https://www.naro.affrc.go.jp/ org/tarc/seika/jyouhou/H19/to07015.html> (Accessed: June 5, 2021).

Oowashi, T., M. Shibata, N. Takahashi and I. Takano. 2014. Everbearing stawberry production treated with crown cooling during summer to autumn season in the plain of Miyagi prefecture. Bull. Miyagi Prefect. Agric. Horti. Res. Cent. 82: 47-58 (In Japanese with English abstract).

Sato, K. and N. Kitajima. 2010. Local heating temperature effects on the growth and yield of strawberries in high-bench culture. Bull. Fukuoka Agric. Res. Cent. 29: 27-32 (In Japanese with English abstract).

Shigeno, T., H. Tochigi, Y. Oohashi and Y. Inaba. 2001. Effect of electric illumination, carbon dioxide supplementation and underground heating on the growth and yield of strawberry "Tochiotome" in forcing culture. Bull. Tochigi Agr. Exp. Stn. 50: 39-49 (In Japanese with English abstract).

Yoshida, Y. and T. Nishimoto. 2020. Propagation and floral induction of transplant for forcing long-term production of seasonal flowering strawberries in Japan. Hort. J. 89: 87-95. 